\title{
How Coaching is Used and Understood by Project Managers in Organizations
}

\author{
Shirley Thompson, Desk-Coach, Ringwood, UK \\ Elaine Cox, Business School, Oxford Brookes University, Oxford, UK
}

\section{ABSTRACT}

Coaching can play an important part in meeting the challenges of project management (Berg \& Karlsen, 2007). However, there remains a lack of research into project managers' perceptions of coaching and the opportunities for using it. This grounded theory study explores the awareness and application of coaching in project management contexts. Analyses of interviews with 14 project managers have indicated that the provision of coaching opportunities is patchy. Findings confirm that organizational culture is important, that where project managers are involved with coaching this can lead to them becoming advocates, and emphasize the need for organizational intervention to maximize the benefits of coaching in this context.

KEYWORDS: coaching; project managers; coaching culture; organizations

Project Management Journal, Vol. 48, No. 5, 64-77 (C) 2017 by the Project Management Institute

Published online at www.pmi.org/PMJ

\section{INTRODUCTION}

he Project Management Institute (PMI, 2013) has highlighted how organizations frequently undervalue project management and put inadequate focus on project manager development despite project management being seen as vital in enabling organizations to improve overall performance (Pant \& Baroudi, 2008). Williams (2008) also confirms the need for successful project management where project managers learn from one project to the next and, indeed, some organizations have embraced collaborative learning initiatives, such as communities of practice, which build on the theory of situated learning in order to support capability-based knowledge (Pattinson, Preece, \& Dawson, 2016). Ramazani and Jergeas (2014), however, recognize that current education does not adequately prepare managers to deal with what they call "the complex realities of the real world" (p. 42), and Palm and Lindahl (2015) point out how project managers are frequently marginalized and excluded from the development opportunities afforded to staff at other levels in organizations. These authors call for organizations to provide more guidance and support "throughout the project management career of an individual" (2015, p. 836).

At the same time as these deficiencies have been identified, a number of authors suggest coaching specifically for project managers as a potential solution to the lack of development (e.g., Graham \& Englund, 2013; Savelsbergh, Havermans, \& Storm, 2016) since it encourages informal learning and guided reflection. Carbone and Gholston (2004) particularly recommend coaching for new project managers, whereas Berg and Karlsen (2007) draw attention to how project management coaching could be an effective tool for helping managers meet their organizational challenges. Ramazani and Jergeas (2014, p. 47) also conclude that coaching has a role in continuous project manager development. Their respondents saw 'strong coaching' programs as critical to achieving a more "multifaceted and systematic approach" to project manager development. Even more recently, Palm and Lindahl (2015) suggest that coaching for project managers may help avoid the stress caused through a traditional lack of ongoing training and support.

Despite promoting the use of coaching for a variety of performance and developmental outcomes, none of the above authors defines coaching in the project management context. In our experience, there are two main uses of coaching: either for skill development in a particular context or for individual development (Cox, Bachkirova, \& Clutterbuck, 2014a). Both of these assume a definition of coaching that is generative rather than advisory or instructive (Feldman \& Lankau, 2005). We therefore work with the broad definition set out by Berg and Karlsen (2007, p. 4) in which coaching is described as "the process of challenging and supporting a person or a team to develop ways of thinking, ways of being and ways of learning. The purpose is to achieve personal and/or organizational goals." This definition implies a knowledge of the 
coaching process rather than a knowledge of context, with the emphasis on reflective practice as a way of thinking and being (Cox, 2013) and is in line with the definition proposed by the International Coaching Federation (2015). We also acknowledge the description of the manager-as-coach put forward by Gregory and Levy (2010), for its emphasis on performance and relationship. Here the process is described as a developmental activity in which "an employee works one-on-one with his or her direct manager to improve current job performance and enhance his or her capabilities for future roles and/ or challenges, the success of which is based on the relationship between the employee and manager, as well as the use of objective information, such as feedback, performance data, or assessments" (2010, p. 111).

A Chartered Institute of Personnel and Development (CIPD, 2011) survey of 601 organizations found coaching by line managers to be the second most effective form of learning and that it was most associated with performance management (43\%) and leadership development (33\%). Performance and leadership are relevant to project managers too. Earlier, the CIPD (2005) training and development survey found that $88 \%$ of organizations reported using internal coaching, but there is no evidence in the literature that this form of coaching is accessed specifically by project managers. In their recent empirical work, Savelsbergh, Havermans, and Storm (2016) identify a range of developmental support mentioned by project managers, but none of them identified coaching. This may be because, as Berg and Karlsen (2007) suggest, although coaching is becoming very popular, people are confused by what it means. Agile methods, which are a key part of contemporary project management, have often been described as involving coaching (Paasivaara \& Lassenius, 2014; Moe, Cruzes, Dyba, \& Engebretsen, 2015) but are often embedded within processes and roles such as 'ScrumMaster'
(Stettina \& Hörz, 2015), which may add to the confusion. Savelsbergh, Poell, and van der Heijden (2015) give some explanation of coaching in their paper on developing project teams; however, they use quite general references to texts at least 10 years old to explain coaching use. Consequently, there was a need to explore how project managers currently understand and use coaching across a range of organizational settings.

Our article therefore reports on qualitative empirical research from a grounded theory study exploring the research question: How is coaching used and understood by project managers in organizations? The question is informed by project managers being part of what Palm and Lindahl call "an exposed group in between the project and the permanent organization" (2015, p. 829). As such, they are often excluded from coaching opportunities initiated by the organization. The study also stems from the personal interest of the first author who, until recently, was a project manager, running software projects in a global IT organization. The hands-on team coach role described by Clutterbuck (2014) is representative of her role at that time.

Edwards, Snowden, and Halsall (2016) have proposed that coaching is multifaceted and is "typically context specific" (p. 88). The lack of uniformity and consistency in coaching practice, they suggest, stems from the fact that professionals are working from different definitions reflecting different perceptions. In our research, rather than impose a definition of coaching on respondents, we wanted to explore how project managers actually understand coaching. Consequently, we deliberately did not define the term 'coaching' for them, but asked for their own understanding.

The article is structured as follows: After a review of the relevant literature to identify theoretical frameworks and gaps in the research, the grounded theory research methodology is described.
Fourteen project managers were recruited from a range of different organizations to enable an appreciation of how they understand and use coaching, either by acting as a coach themselves or through being a 'coachee,' in other words, the person being coached. Findings are then presented that show a variable awareness of what coaching is, and highlight the extent to which organizational culture impacts the perceptions and subsequent use of coaching, with awareness and experience of coaching leading some project managers to overcome organizational constraints and become advocates or champions of coaching.

\section{Literature}

A range of business, project management, and coaching literature was reviewed to find studies relating to how project managers understand and use coaching. This literature is reviewed under three headings: (1) project managers as coaches, (2) project managers in receipt of coaching, and (3) the role of a coaching culture in organizations.

\section{Project Managers as Coaches}

A search of the project management literature revealed 'project manager' and 'coach' as terms that rarely appear together and then, as suggested earlier, when they do it is only to recommend coaching for project manager support rather than to present research. Other literature discusses coaching, but does not identify project management as a distinct context for study. In their handbook, for example, Cox, Bachkirova, and Clutterbuck (2014a) discuss a range of coaching contexts but do not distinguish project management as a separate genre. They do, however, include a chapter on the 'manager as coach' and there are peer and team coaching chapters that may also be relevant to the project manager context.

The manager as coach literature itself has begun to expand in recent years. Ellinger, Beattie, and Hamlin (2014) explain how the use of coaching for developing employees has long 
been a core managerial activity, with the human resource function frequently being devolved to line managers. Surveys by the CIPD in 2006 and 2007 confirmed this shift; however, despite an increasing interest there has been little empirical research in the area. In a review of the literature by Beattie et al. (2014), it was argued that one of the major weaknesses of managerial coaching is a lack of empirical research showing the impact of this type of coaching on learning and performance. These authors confirm how, in the absence of support from the research, "organizations, managers, and employees have been presented normative and idealized notions about coaching" (2014, p. 185), highlighting how the idealistic framing of managerial coaching in this way may overlook the challenges managers encounter. Concluding their review, they stress the need for research into factors influencing the managerial coaching process.

Beattie et al. (2014) and Ellinger et al. (2014) both include team coaching within managerial coaching, suggesting that the 'manager as coach' should adopt a team approach rather than an individual approach with tasks. Hagen and Aguilar (2012, p. 381) also claimed that coaching is a "core activity" of management and leadership and that team members' learning outcomes are likely to be improved if the team leader has coaching skills. They too confirm that there is very little research in the area of managerial coaching but that it is vital to understand its role, particularly in the context of team development. McKee and Eraut (2011, p. 29) point out that the 'manager as coach' concept "does not really unpack either the complexity or the scale of learning which is often needed in a team."

Other texts also refer explicitly to a project manager having a role as team coach. In a case study from the electronics industry, Carbone and Tippett (2004) explained how teams could be coached on the process of risk management, whereas other authors mention leading, empowering, or developing the team (e.g., Box \& Platts, 2005; Brill, Bishop, \& Walker, 2006; Schmid \& Adams, 2006) or giving feedback and developing others (Gillard, 2009). Earlier, Lee (2009, p. 456) had highlighted the four roles of a project manager: "leader, manager, facilitator, and mentor/coach."

Hackman and Wageman's (2005) conceptual paper introduced a team coaching model that explained the functions that coaching provides for the team and included recommended timing and conditions for coaching activity. Similarly, Thomas and Mengel (2008) mentioned emotional skills as necessary to motivating and coaching the team; they offered a model of project manager development and highlighted the need for critical reflection. More recently, Clutterbuck (2013) suggested that team coaching is needed "when a new team is being created and needs to hit the ground running" and "when an existing team is not performing as well as it could" (p. 20). Both these situations seem directly relevant to project management. Clutterbuck also emphasized the importance of conversations between team members and acceptance by the team that a coaching approach is beneficial. Team coaching, he argued, has multiple definitions and is "only now emerging as a clear area of practice that requires specialist knowledge, skills, experience and supervision" (2013, p. 18). Clutterbuck (2014) further suggested that definitions of team coaching identify achievement of a common goal and pay attention to both individual performance and to group collaboration, a definition that seems to place the emphasis on "achieving a solution to a specific problem, rather than building the team's overall capacity" (p. 272).

As noted, although the literature pays some attention to managerial coaching and to the use of coaching with teams, it seems to say nothing specific about the coaching project managers receive or indeed the coaching they are doing and how they perceive it. This is a significant omission, which this study begins address.

\section{Project Managers in Receipt of Coaching}

Over the past decade a number of authors have mentioned coaching briefly as being useful in relation to project manager skills development: Jiang (2002) quoted a long list of soft skills requirements, which included coaching; Carbone and Gholston (2004) recommended coaching as a follow-up to training; and both Kombarakaran, Yang, Baker, and Fernandes (2008) and Walker and Dart (2011) highlighted 'people skills' as a benefit of receiving coaching. More recently, Hans and Rwelamila's (2012) survey of the South African information and communication technologies (ICT) sector advocated coaching to improve the expertise of those who are less experienced, and Pollack, Costello, and Sankaran (2013) also showed how coaching helped people when implementing a new project management software system.

Although coaching is recognized as useful, however, there appears to be very little research on how project managers themselves perceive coaching or access it for their own development. Savelsbergh et al. (2016) similarly point out that despite recognition in some contexts of the advantages of coaching, "only a small majority of the project managers have taken the time and effort to discuss their most important learning experiences with someone responsible for their development" (p. 566).

In addition, although coaching appears to be promoted as important for project managers, there is still much uncertainty and ambiguity around what coaching is, even in coaching circles (Ives, 2008; Ladyshewsky, 2010). Passmore and Fillery-Travis (2011) also suggested there is no coherent approach that defines coaching. It could be this uncertainty that contributes to the reluctance by organizations to embrace coaching as a developmental strategy for all managers. As Hagen and Aguilar 
(2012) indicated, even though there has been an increased focus on coaching within the practitioner literature, organizational practice has been slow to move in the direction of implementing coaching or coach training.

\section{Coaching Culture in Organizations}

The importance of a coaching culture in promoting engagement with coaching has been highlighted by a number of authors (e.g., Cox, 2012; Gormley \& Van Nieuwerburgh, 2014).

Anderson, Frankovelgia, and HernezBroome (2009) also linked a coaching culture with more trust and openness in the organization, suggesting that this leads to more participative and transparent decision making. In their survey of U.S. business leaders, these researchers found the range of organizational benefits resulting from the development of a coaching culture included: employee performance, engagement and retention, collaboration and teamwork, and an improved ability to execute strategy and adapt to change.

Gormley and van Nieuwerburgh (2014) similarly provide a definition of coaching culture that emphasizes how vital this aspect is to promoting engagement in coaching:

“Coaching cultures exist when groups of people embrace coaching as a way of making holistic improvements to individuals within their organisations through formal and informal coaching interactions" (p. 92).

and Hawkins includes the idea of engagement and development, suggesting that:

"A coaching culture exists in an organisation when a coaching approach is a key aspect of how the leaders, managers, and staff engage and develop all their people and engage their stakeholders, in ways that create increased individual, team and organisational performance and shared value for all stakeholders" (2012, p. 21).

Clutterbuck and Megginson (2005) had a similar perspective, proposing that the coaching culture can be exemplified by a commitment to grow both the organization and the people within the organization. Several authors pick up on this commitment aspect, and have identified the important role played by the leaders and managers of organizations. Anderson and Anderson (2005), for example, stressed the need for leaders to be coaches if a coaching culture is to be developed with the resultant performance benefits; Giberson et al. (2009) demonstrate the importance of leaders on organizational culture in general, whereas McComb (2012) suggested "a high level of participation is required from a senior leader when an organization is trying to establish a coaching culture" (p. 91).

According to Passmore and Jastrzebska (2011), the development of a coaching culture involves a journey of five stages: informal external coaching, the strategic use of external coaching, coaching for all staff, coaching for every stakeholder and, finally, coaching externally to a wider community. However, Evans (2011), in researching managers in the police service, also suggested that coaching in organizations often exists as "a messy and complex social system of connectedness and situatedness" (p. 80), suggesting a less linear trajectory and identifying how individual perceptions of coaching vary noticeably between research participants.

According to McCarthy et al. (2015) there is also an identified link between the culture of an organization and the possibility for managers to display coaching behaviors. Ladyshewsky (2010, p. 302) similarly argued that coaching in the workplace should be "part of an overall organizational development and performance management philosophy." He suggested coaching is a core skill required of managers that should be emphasized in organizational development initiatives. However, as Pousa and Mathieu (2010) pointed out, organizational emphasis on short-term goals, such as those inherent in a project management setting, can decrease the likelihood of managers using coaching behaviors. Milner and McCarthy (2016, p. 8) suggest that although managers in organizations are increasingly expected to coach their employees, "not all organizations provide the necessary training."

In summary, coaching culture can be characterized as being woven into the fabric of the business (Turner \& McCarthy, 2015, pp. 2-3). It should be viewed as a part of organizational culture and, as a result, the coaching culture reflects the patterns of assumptions and actions that influence the organization as a whole and could be seen as influencing how coaching is perceived, accessed, and used by employees.

The findings of this review are useful in that they highlight the very limited attention paid thus far to research into how coaching is used as a development strategy for project managers. There appear to be many recommendations that coaching be adopted (i.e., Carbone \& Gholston, 2004; Hagen \& Aguilar, 2012; Savelsbergh et al., 2016), but very little empirical research. The review therefore implies the need for a study using a methodology that can uncover what is actually happening on the ground in project manager contexts, in order to understand how coaching is understood and used to support project management as a vital function.

\section{Methodology}

The literature review revealed a specific lack of research in relation to how project managers perceive or use coaching. Therefore, it was seen as appropriate to use a grounded theory research methodology (Strauss \& Corbin, 1990; Charmaz, 2014), to enable exploration of a range of project managers' attitudes about and experiences in coaching. This would build an awareness about what is actually happening in the project management context from a project manager's perspective.

Following the grounded theory approach to data collection and analysis, three rounds of interviews were 


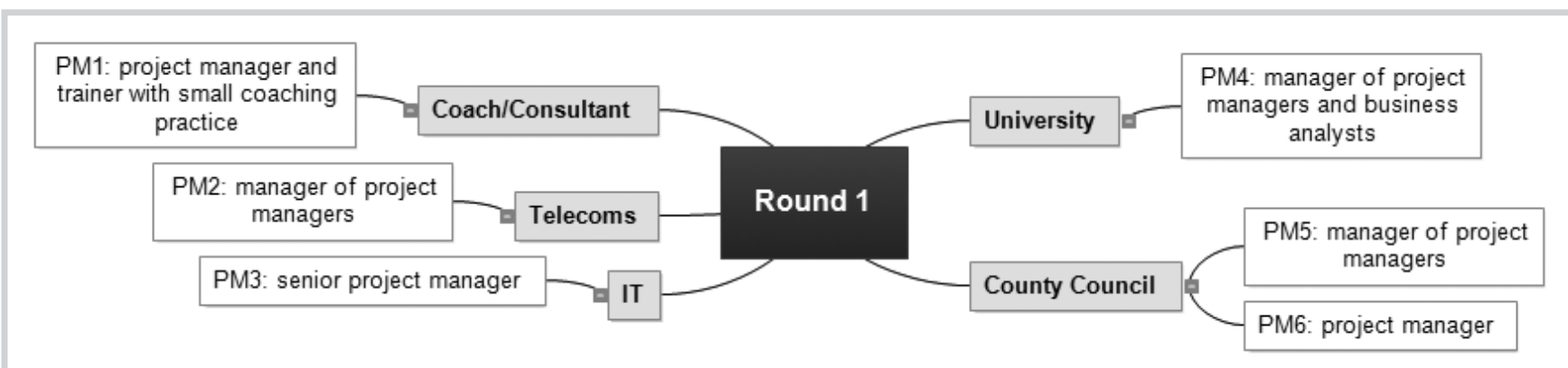

Figure 1: Round 1 participants.

conducted using an iterative theorybuilding strategy. In Round 1 (see Figure 1), we purposely selected six project managers who were responsible for the effectiveness of other project managers and project management processes. After Round 1 data analysis, it became evident that we needed to target those who had first-hand experience of 'in-house' organizational coaching programs as well, so in Round 2 five more senior project managers were selected from larger organizations. For Round 3, three project management consultants were targeted in order to bridge a gap between the lower and higher levels of management.

All participants were established project managers from a variety of organizations. In total, 14 interview participants were drawn from the PMI network of Project Management Professional $(\mathrm{PMP})^{\circledR}$ certification holders, or from the second author's network of coaches of project managers. They came from a range of large and small companies, across the public and private sectors, and were contacted directly through the PMI United Kingdom Chapter network or LinkedIn.

Figures 1, 2, and 3 show the actual participants and their backgrounds. Figure 1 shows the generalist project managers interviewed in Round 1 (PM1, PM2, etc.); Figure 2 shows senior project managers interviewed in Round 2 (SPM1, SPM2, etc.), and Figure 3 shows coach-consultant project managers in Round 3 (CPM1, CPM2, etc.). In line with theoretical sampling, in Round 2 we needed to seek views from larger organizations to gain more insight into the emerging axial codes. Thus insights were gathered from participants in larger organizations where there seemed to be more coaching options for employees. Round 3 was completed with three project management coachconsultants with the aim of reviewing the findings using coaches' viewpoints. Although none of these project management consultants had formal coaching qualifications, coaching was part of their commercial offering.

Interviews were semi-structured and lasted an average of 45 to 55 minutes. Interview questions included explorations of how the project managers had made use of coaching, whether they had carried out coaching, how they had learned about coaching, and what coach training they had received. Later interviews (Rounds 2 and 3) used questions reflecting the analysis of data collected in the previous round. Example questions included: What do you understand by coaching? Have you ever been coached? How long were the sessions? How many sessions were there? What was the motivation for the coaching? Each participant was provided with an interview transcript for validation.

The analysis process followed Strauss and Corbin (1990). This involved alternating between data collection and analysis to follow up on developing theories, cut through biases, and to examine further literature as the findings

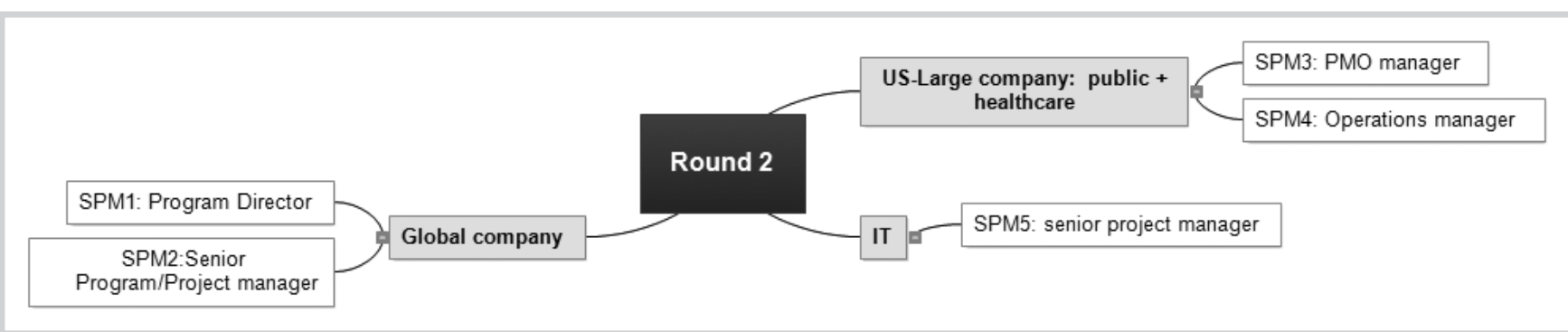

Figure 2: Round 2 participants. 


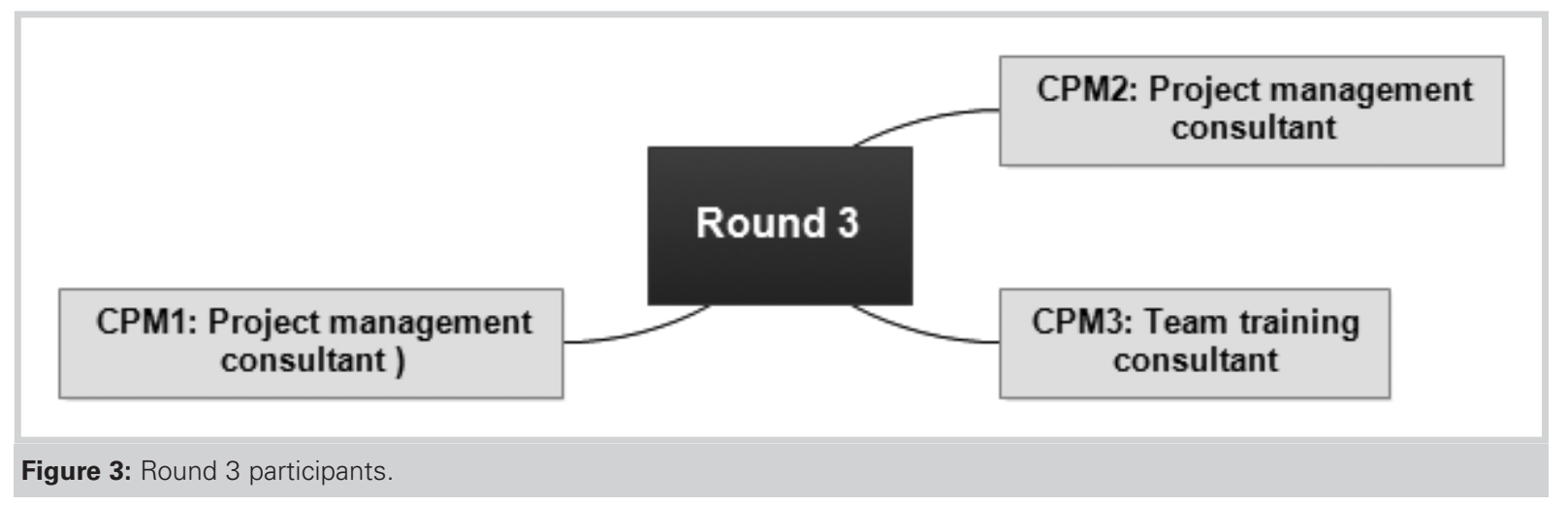

emerged. Open coding was used with each transcript, and mind-mapping software (MindView) provided a pictorial view of the interviews, first through open codes, then later by manipulating the mind map around axial codes and core categories. Three axial codes emerged from the early Round 1 interviews: awareness of coaching; experience of coaching as a project manager; and whether the organization supported opportunities for coaching in the workplace. Analysis of Rounds 2 and 3 thus brought more breadth and depth and the reinforcement of the relevance of organizational context. Subsequently, selective coding produced the three categories presented next.

\section{Findings}

Findings are presented under three main headings that reflect the selective codes revealed by the grounded theory analysis: (1) perceptions and definitions of coaching, (2) opportunities for using coaching, and (3) from initial awareness to champion.

\section{Perceptions and Definitions of Coaching}

In addition to the revealing differences in the opportunities project managers have for coaching in their organizations, our findings also uncovered two aspects of project managers' perceptions of coaching: (1) that coaching is similar to other helping approaches, particularly mentoring, and (2) that coaches need specific soft skills.

\section{Coaching is Similar to Other Helping Relationships}

In addition to differing perceptions of the coaching relationship itself, project managers have a variety of ideas about the differences between coaching and other helping relationships, with participants conflating coaching and mentoring or being intent on comparing the two. Several have mentioned the similarity between the two concepts:

Coaching and mentoring are interchangeable for me [SPM1]

[Coaching and mentoring] I see them as the same [CPM1]

Either mentoring or coaching is supporting another person with a 'shared goal' [SPM2] For me mentoring is halfway between coaching and training [PM1]

However, there were some attempts at differentiation. One project manager suggested: "Mentoring is for career support, positioned for longer term, [and is] skills oriented-mentoring is expected as part of internal project management accreditation, especially for higher levels" [PM3]. His explanation was that:

[Mentoring is] more prescriptive than coaching-i.e., more telling" [whereas] coaching takes a broader perspective good for more complexity [. . .] an experienced sounding board, probing questions to provide answers, explore personal/career/life, a broader exposure across variety of things. [PM3]
In some cases, the opposite definition was expressed, in other words, that mentors are less prescriptive:

[Mentors are] not going to be telling you 'oh yeah you need to fill out that form or do this or get that signed off,' they're very much going to be talking about the softer skills, asking how would you tackle this issue, 'how would you break this news to this senior stakeholder' [SPM1]

It was even thought that a lack of definition may provide flexibility in what is discussed: One participant suggested it enables exploration of "a broader variety of things personal/career/life" [PM3]; and also in what form the coaching or mentoring takes "Use whatever works" [PM3]. However, it was acknowledged that this may not help those new to the experience to understand how it works: "coaches [and mentors] do understand what it really means, but for those who are coachee and mentee it is very confusing for them" [SPM2].

For other participants, features of the relationship (e.g., focus, topic) enabled them to distinguish between the two: "Coaching has short term focus, for issues in the moment. Mentoring is positioned more as longer term, career support, e.g., mentor a junior person who wants the skills you have" [PM5].

In the literature, mentoring is generally accepted as relating to situations in which the mentor is very knowledgeable about the environment and/or topics of conversation. A mentor is usually 
more senior to the mentee to enable knowledge transfer or for advice to be sought and given (Garvey, Stokes, \& Megginson, 2014). Most participants agreed:

Usually your mentor is seeing what needs to be done and is helping you prepare yourself and set yourself up for promotion [SPM2].

[A mentor is] an experienced sounding board [PM3].

Others confirmed coaching's 'justin-time' benefit:

Coaching is on the job; [the coach] could be your manager or someone on the project [2-G2]

[Coaching is] having access to someone who you're not working with day-to-day with completely different views to job, work environment etc." [PM3]

While some commented on why occasionally the term coaching was not used:

It's strange that people don't use the term coaching, I'm using it more and more often [. . .] especially with my mentees, and saying what we're entering into, rather than mentoring where you kind of pick my brains and I try and understand what it is that you're trying to achieve and help you get, build a path to get there. A couple of my mentees have said we're much more into coaching, because they've said: 'Oh can we do dummy interviews, can you walk me through presentation skills, things like that?' [SPM5]

Some consultant coaches, such as CPM3, were not keen on using the word coaching, even though a coaching style may be used: “it doesn't suit everybody and it doesn't suit every team; it could work very well say in a housing team, but it probably wouldn't work very well in an IT team" [CPM3]. Mostly this participant offered team development solutions, with (external) coaching being one of the preferred tools. This participant also considered that project managers have a particular style/reputation, which shows the preference for finding terminology that is acceptable to the audience:

They would love to get together for a day and talk about sharing practice you know. I was working at $X X X$, what did you do about, how did you approach it, what were the issues? They would call that 'sharing good practice,' not reflective practice. [CPM3]

One coach-consultant had an approach of providing external coaching for a company and encouraging internal mentors as well as coaching:

So we're running these feedback sessions and we're now finding out what they want, to help them go forward. And, we're now about to set up coaching and mentoring. And the two are quite different. What we're going to try and do is to get some of their own people, the more senior project managers to mentor the more junior ones, and then for someone like myself to come in and coach. [CPM1]

In this section, the understanding of coaching by project managers revealed a certain lack of clarity in the definition of coaching in relation to practicalities and focus. However, some participants saw the perceived similarities between coaching and mentoring as beneficial, suggesting that it enables flexibility. Indeed, as Turner and McCarthy (2015, p. 3) note, "the majority of business coaching is done internally in organizations although it is not always explicitly labelled coaching." Other participants in the current study saw the terms coaching and mentoring as restrictive, particularly in some settings, and preferred to tailor the intervention to the audience. These different understandings of the definitions and uses of coaching are partly indicative of the lack of definition and clarity in the coaching field itself (Garvey, Stokes, \& Megginson, 2014; Cox, Bachkirova, \& Clutterbuck, 2014b). However, it could be that they are exacerbated by a lack of organizational consistency in policy and provision and by a lack of training and support as highlighted earlier.

\section{Coaches Need Specific Soft Skills}

Project managers' perceptions of coaching were augmented by recognition of the need for coaches to possess certain soft skills and for these to be beneficial for project managers to learn as well. Some participants acknowledged soft skill training through manager training (e.g., "three hours soft skills training for coaching" [SPM5]). Others, like this senior manager, had completed several courses: "There are opportunities for courses which are online, where it explains what this means, what to expect, for example, ask open questions, be open and honest, if people ask for feedback, then give feedback" [SPM2]. In another larger organization that had introduced a coaching culture as part of an organizational change program, it was noted that some project managers "were trained on how to coach, and then sat down with managers, acting as coach, helping those managers through the change that they had to do" [PM5]. Observations from participants in the study also suggest that soft skills are a key aspect of learning to coach and that these skills can be supported by coaching itself. For example, PM1 explained: "you need some sort of repetition of learning-coaching after training helps you talk about what happened" [PM1].

Another view from a project manager, who found his own coach, was that coaches need to be interested in people: "People-oriented individuals are coaches, those who've taken coaching courses, and feel they'd like to coach people" [PM3]. One senior manager explained:

One of the key pieces of coaching is that there [needs] to be a relationship built with the coach, for the coach to be able to give that specific direction and fill that specific need that I'm looking for. [I've] reached out to different people [for] leadership, for becoming more professional, PMO job. [SPM3]

The importance of soft skill development has also been identified as 
an important developmental need for project managers themselves (Jiang, 2002; Pant \& Baroudi, 2008) and some participants reported that specific soft skills might be usefully acquired through learning to coach:

I would put a lot of emphasis on soft skills to make you a great project manager. [PM5]

I'd say more often coaching tended to address soft skills issues than hard skills training stuff. [PM2]

Emphasis is on people side of project management. [PM4]

"I think there are tools and techniques that can help you ... especially in the change environment we're in" and "open questions and silence certainly help" and "I think it needs to be part of the tools of project manager training." [PM6]

\section{Opportunities for Using Coaching}

In larger companies, where a coaching culture exists, it was noted that there are often policies whereby leadership potential is supported through the provision of formal coaching support. Project managers are sometimes included in that provision. Indeed, one participant from a telecommunications company reported that his organization had an accreditation program for project managers, which involved formal coaching:

Project managers take responsibility for the coaching, arranging the meetings, we'd normally ask the applicants to find their own coach. If they struggled, we'd help them. We had a list of people training up (as coach) but we didn't offer that list. If the candidate chose someone not on the list, we'd offer that person the coach training. The only hard rule was that it should not be their line manager. [PM2]

Across larger companies, there appeared to be a clear desire to ensure all project managers follow project management processes and a recognition that accreditation encourages the use of coaching. For example, PM6 confirmed "we're audited." Two other project managers confirmed that coaching is: "a mandatory part of the accreditation scheme" [PM2] and supports "conformance to process or procedures" [CPM3]. CPM3 also suggested coaching is useful when "there is a difficulty or a challenge."

Another large organization had different structures for permanent and contracted project managers. SPM1 explained how, for permanent staff, "we take a more structured approach as they're the people who will grow into more senior programme manager positions. The idea of our mentoring and coaching programs is that we try and equip people to match their aspiration." [SPM1]

This participant also noted that contracted staff: "fall under the wing of program managers [who] have an inherent responsibility to coach, to provide tips and advice, review project plans [etc.] that's ongoing 'on the job' regular coaching." [SPM1]

However, in organizations where there appeared to be a more informal approach to coaching, there seemed to be a risk that the coachee did not know or understand that coaching was taking place. One manager described how his organization had embraced coaching: "there are internal coaches even if not widely publicized [and] career coaching." [PM5] Similarly, a supportive coaching style of questioning, could be missed by the uninitiated and not labeled as coaching, thus being seen as just part of informal management conversations. One participant shared how he had clearly been influenced by a managerial coaching style: "I've certainly been a recipient of it, and my opinion is it doesn't always have to be the formal setting: it can just happen with your line manager." [PM6] This informality was seen by one participant as having a real benefit: "if someone has an issue, I think you can just drop into it, they don't have to recognize they're being coached just to benefit from the tools." [PM6]

If coaching proceeds informally it may make an impression on the coachee, as suggested here, but it could be argued there is a missed opportunity to correlate the beneficial experience with a definition of formal coaching.

The only mention of contracting in the current study was in the context of external coaching, in which one participant explained how contracting for a program of sessions was carried out with an accredited coach where the first intake session was usually free and of the six subsequent sessions "part of the sixth would be close-out, measuring outcomes, thinking about process and how they're going to use it going forward." [PM1] This omission may reflect a lack of understanding in relation to the formalization of coaching and may be what contributes to the lack of commitment to the coaching relationship in some organizations. For most, it seems that in the project manager context the formalities of setting up a coaching relationship are of secondary importance.

It became clear that there was a range of informal and formal coaching opportunities in companies and that some project managers may be included, but this was not always the case. For example, project managers may be included in leadership programs, but almost definitely not if they were employed under temporary contracts. It was also reported how uncertain work environments affect developmental opportunities:

“[We] call it here 'survivor syndrome.' You're lucky to be left when we're starting to do all the lay-offs, restructures with everything else, and so it's not so much that I owe you something and you're an asset but it's more, you're lucky that you still have a job and, you know, and so it kind of really changes the focus of what we, how we invest in people now." [SPM4]

In some organizations there may also be organizational barriers to coaching that need to be overcome. For example, this senior project manager's plans for coaching for project team members 
yielded an immediate response from a new director:

... You're a project manager and we just need to focus on the project that you've been assigned for this year. There's no money in the training budget and I don't see the need for us to be spending time on these items, you just need to make sure your projects come in on time. [SPM4]

The availability of opportunities for coaching provided by organizations is therefore very important. Another manager from the public sector confirmed that "If you have a variety of different ways of coaching in an organization, that's beneficial, it's about finding the right way to develop the people that you have" [PM5]. This participant also spoke about the need for a range of developmental provisions: "having a toolkit of things and coaching would be one of those, so it becomes part of the job." [PM5]

Analysis also revealed how many of those undertaking coaching in organizations have minimal training as a coach, depending on the culture of the organization. Some participants, for instance, received coach training through manager training (e.g., "three hours of soft skills training for coaching." [SPM5]) Others, like this senior manager, had completed several courses: "There are opportunities for courses which are online, where it explains what this means, what to expect, for example ask open questions, be open and honest, if people ask for feedback, then give feedback." [SPM2]

In another larger organization that had introduced a coaching culture as part of an organizational change program, it was noted that some project managers were trained in coaching "and then sat down with managers, acting as coach, helping those managers through the change that they had to do." [PM5]

In some smaller organizations, however, coaching provision was not widespread. Some had established processes that were used to offer formal coaching options; in others, individuals were entrepreneurial in seeking out coaching solutions in spite of organizational inertia. One of the Round 1 participants gave the following 'guesstimate' of coaching opportunities for established project managers:

"A third (of coaching) would be embedded training, a third would be a particular issue they'd come up against, a third about what they perceive they need to be better at, general stuff they wouldn't go on a three-day course on." [PM1]

In Table 1 we summarize the varieties of ways in which the individual project managers experienced coaching.

Table 1 highlights that project managers may have external experience in being coached or acting as coach and can bring that experience to their work environment. They may seek coaching with a buddy or more formally for personal development, and they may encourage others to appreciate coaching through a buddying experience. It is clear that there can be a big difference in the take-up of coaching opportunities. For example, one project manager proactively sought support from three coaches [SPM3], whereas there were those who apparently relied only on their managers to nurture them. [PM3]

An emphasis on culture was also noted. One public sector manager in particular identified a difference between organizations that are task focused and those that value soft skills:

It depends on the organization, project managers who want to use more soft skills will struggle in the type of organization that wants someone to go in and do it. Task-oriented project managers will be fine if that's where they end up, particularly IT projects for example. [PM5]

In this section we reported on how coaching opportunities within organizations are influenced by decisions and attitudes toward one-to-one support and how take-up of coaching by participants from both larger and smaller companies is affected by this coaching culture. As would be expected, it appears that the organization plays a big part in setting expectations for project managers' development, which may or may not involve coaching. In some companies it was observed that there are formal coaching processes in place and employees develop an awareness of what coaching is, the skills that can be developed, and how it can work for them. In other settings, however, although a coaching style may be used by managers, it is not always identified as coaching by employees and so awareness is not generated. Where formal training is provided, the development of soft skills was seen as a possible

\begin{tabular}{|l|c|l|l|}
\hline Participant & $\begin{array}{l}\text { Receiving } \\
\text { Coaching }\end{array}$ & $\begin{array}{l}\text { Acting as } \\
\text { Coach }\end{array}$ & \multicolumn{1}{|l|}{ Introduction to Coaching } \\
\hline PM1 & Y & N & Through coach training \\
\hline PM2 & Y & N & Via executive coaching \\
\hline PM3 & Y & N & Through receiving coaching \\
\hline PM4 & Y & Y & Managerial training \\
\hline PM5, PM6 & Y & Y & $\begin{array}{l}\text { Managerial training or project manager } \\
\text { training for 'change' }\end{array}$ \\
\hline SPM1, SPM2 & Y & Y & Leadership training or being a mentor \\
\hline SPM3, SPM4 & Y & Y & External (sports or volunteering) and buddying \\
\hline SPM5 & Y & Y & Managerial training \\
\hline CPM1 & N & Y & $\begin{array}{l}\text { Expertise gained through consultancy, and } \\
\text { training experience; one had sports-related } \\
\text { CPM2 }\end{array}$ \\
CPM3 & & & experience. \\
\hline
\end{tabular}

Table 1: Varieties of ways project managers experience coaching. 
outcome, not only for coachees but possibly also for coaches themselves, thus meeting, in some way, Jiang's (2002) call for more development in this area.

\section{From Initial Awareness to Champion}

Savelsbergh et al. (2016, p. 566) found that the most popular developmental aspiration for project managers was coaching other project managers, which in turn points to a desire to help others advance. In our study, we found evidence of this aspiration in practice. It seems that any positive experience that individuals have of coaching may, in turn, encourage them to become supporters or champions of coaching. Our findings suggested that awareness of coaching can come through coach training [e.g., PM5, SPM2, SPM4] or through being coached [PM2, SPM3] either in a formal scheme or informally. Then, once individuals have some experience of what coaching may do for them, it appears they take more responsibility for seeking out coaching opportunities, ultimately becoming champions of coaching. Even where coaching was not readily available, or a more informal approach was evident in the organization, some project managers took the initiative and championed buddying or coaching projects themselves.

Where there were few or no formal expectations of coaching within the organization, some participants were still aware of the opportunities offered by coaching. One explained how: " $a$ former leader recommended I get a coach if I wanted to be a professional." [SPM3]

Another participant, who had experienced a coaching course, related how he had found an internal coach despite the fact that "the list of available internal coaches is not well advertised." [PM3]

Some participants were so motivated by what they knew about coaching that they wanted to promote it to others despite obstacles within their organizations. Some recognized they could help other project managers through using a group coaching format of sharing experiences that helped them learn. One participant had first encountered coaching through shared group learn- ing, presented as peer group coaching. He commented that it was "sometimes good to have a project manager who understands where you're coming from, and do it in the right way, to help you think through your problems." [PM6]

In addition, the formal accreditation process championed by PM2 had coaching content just because of the philosophy of the manager: "[I was] on a three-day course on executive coaching and I just saw the light and became the champion of that method." [PM2] This participant ran a small team of project managers who were formally managed by a peer and he was responsible for the way projects would be run across the organization. He also explained that to get a community off the ground is a challenge: "[building a project manager community is] really difficult to do as project managers tend to work on their own."

In some organizations, individual champions of coaching may be needed to support project manager development, due to little other organizational support, as identified by PM2: Coaching was a revelation to project managers, as they hadn't realized that they could use someone else as a sounding board and still be seen as intelligent and worthy as a project manager even though they asked for help." [PM2]

In others, managers and project managers often take a leadership role in establishing a community of project managers, or use team meetings to coach the project managers in their group. These communities for sharing practice seemed good, but apparently have faced challenges. One of the external consultants commented how these attempts at creating a community can "come and go" [CPM1], and one of the initiators admitted: "I tried three years ago to create a community . . . this time I've placed a lot of emphasis on making it relevant, highlighting the benefits the community can bring." [SPM5]

Another manager indicated she wanted to champion coaching: "I personally want coaching as part of the [framework]. The project management office will be a center of competence [for the], coaching of soft skills, process." [PM4] Champions seemed keen that project managers share practice for their development. PM5 described how this was undertaken:

I started by saying 'let's talk about each other's projects-'just explain what you're doing so we've all got an idea of what everyone else is doing, and you're not working in a silo and actually you may be able to share something with us.' [PM5]

There seems to be a natural drive in champions to support people who are interested in personal development and value feedback, through coaching (SPM3, SPM4, PM5, PM4, and SPM5). For example, one champion explains how coaching opportunities arise for her through giving good feedback: "the kind of coaching I probably do the most, is in a mentoring relationship where folks come and say, I've never really facilitated a meeting, you know ..." [SPM4] This participant also suggested that instigators of coaching need to have certain values:

\footnotetext{
I absolutely agree [. . .] that coaching comes from somebody who has intrinsically had that as a value themselves, that it's kind of like folks' desire, or need, or desire, or believe that it's important to give back to the community to non-profits, to be philanthropic [SPM4].
}

In addition, champions of coaching may also be natural coaches as the same participant explains:

He has just an amazing gift to be a teacher, to be a natural coach in whatever he does at all levels. So he will have a payroll clerk, [whose] only desire is to come in and punch the clock, get a pay check and do the same job for 10 or 15 years, and he'll help her see the good in herself and the belief that she can do something different, better, or learn more, or take on a new task and it's $\mathrm{OK}$, that her life will be better and richer, in a different way. [He was] a very, very strong peer coach and mentor for me, I achieved several of my successes directly because of that relationship and that peer feedback and coaching [...]. [SPM4] 
We suggest that findings emphasize the 'bottom up' enthusiasm for coaching, which can occur in some organizations despite a lack of a formalized coaching policy. It demonstrates how project managers are concerned for the development of their teams and look for ways to support them.

\section{Discussion}

In this article we reported qualitative data from a small-scale grounded theory study. The findings draw attention to some valuable issues in relation to how coaching is perceived by project managers, how they make use of it, and also the value of a coaching culture in organizations. Three useful findings have been presented.

First, the study found that although project managers recognized that coaching was useful for developing soft skills as suggested by Pant and Baroudi (2008), across the project management field there was some uncertainty about how coaching differed from other support mechanisms, such as mentoring. Project managers described how in their experience coaching and mentoring were often interchangeable. This is a widely discussed issue in the coaching literature, with some commentators arguing that what makes coaching and mentoring distinctive is merely "the context in which they happen" (Garvey, 2014 , p. 363). Indeed, in the project management context where the specific idea of agile coaching has developed, Adkins (2010) suggests that coaching takes on the "dual flavor of coaching and mentoring," since in the context of agile coaching the coach does not only help coachees to see new perspectives and possibilities but also mentors them. Thus we can see that the diversity of perspectives and definitions held by participants in our study is partly generated by the literature from different contexts. In defense of the diversity of perspectives found in his study, Evans said (2011) that a variety of perspectives could be seen as supporting the idea of constructivism in sense-making, which in turn "undermines simplistic and deterministic claims of the general efficacy of coaching programs" (p. 81). The perception of our participants in particular, was that this lack of clarity is probably not detrimental to the support offered, since it provides flexibility within the relationship. Thus, this lack of definition should not deter large or small organizations from setting out their own consistent policies and provisions in order to reap the benefits of coaching.

The second finding related to how the opportunities for coaching by or for project managers varies within organizations and are attributed to the availability of organizational support. It was noted that project managers valued informal coaching as much as formal coaching, but that a lack of understanding of overt contracting may prevent otherwise enthusiastic coaches from being able to realize the benefits fully. As Fillery-Travis (2015) points out: an informal approach to coaching may mean that the coach neglects to pay attention to the contracting element, normally accepted as important within the coaching process. Ferrar (2006) even argues that the responsibilities of manager and coach are incompatible because the fragile psychological contract and the management 'mind-set' operate as obstacles to successful coaching. The lack of focus on contracting may also be because contracting is not well defined in the literature and lacks theoretical framing (Egan \& Hamlin, 2014) or it could be that, as Raelin (2012) suggested, a manager's role already encompasses these expectations through multiple roles such as: 'teacher, educator, coach, developer, and facilitator' (p. 819). Raelin argued that there is an expected emphasis on facilitation as an emancipatory framework for 'mutual (rather than unilateral) learning, deep understanding and insight, and collaborative action' (2012, p. 820).

Many project managers also had insufficient awareness of coaching to seek opportunities themselves, and were reliant on others to make it accessible to them. In relation to the support available, encouragement through training and resourcing was seen as necessary in order for project managers to use coaching effectively. Acknowledging that this was a small-scale study, we found that bigger companies tended to have more structures for the delivery of coaching programs and possibly a more distinct coaching culture. Our analysis therefore suggests that organizational culture is a crucial backdrop to the coaching support provided for the development of project managers. We argue that not only are coaching opportunities for project managers underpinned by contextual factors within the organization, but that these also affect take-up and attitudes to coaching. Our study supports Gormley and van Nieuwerburg (2014) in recommending that a mature coaching culture can provide support for all individuals in an organization, but in relation to project managers in organizations, this is an area that would benefit from a larger study.

Third, one of the key findings in the study is that where a coaching culture is not mature and coaching is not readily available to project managers, some will take the initiative and seek out coaching for themselves or even champion coaching projects for their colleagues and teams. Once awareness is raised, therefore, project managers who have some knowledge or experience of coaching can shift to becoming internal initiators and supporters of a coaching culture. The study found that those project managers who recognize the benefit of coaching become champions of coaching within their organizations. Champions (as leaders, project managers, or consultants) usually have some experience in being coached and become self-motivated to coach after experiencing it. They then spread awareness of coaching and its benefits often in an informal way through shared practice or mentoring rather than overtly through coaching. It was clear that often champions of coaching bring their knowledge of coaching 
to their work role: they are interested in creating a coaching culture in their organizations and recognize the value of the skills project managers could develop through shared practice to help themselves and other project managers.

We suggest this finding points to a journey or progression of understanding of coaching by project managers. Project managers' understanding shifts from an awareness of what coaching is, through the opportunity to experience coaching-either as a coach or a coachee-to eventual championing of coaching within the organization. Kretzschmar's (2010) research in the voluntary sector centered on client readiness for coaching, which similarly included the necessity of having knowledge about coaching and having access to a coach. The current study has found a corresponding need for readiness, awareness through organizational provision, and opportunities for informal or formal coaching, either as coach or coachee. What our study also found was that if organizational support was not available, some project managers deemed coaching important enough to undertake it independently and these were the people often most motivated to become champions of coaching in the organization. It is suggested that organizations could capitalize on this grassroots motivation to build their coaching culture. Allan (2007) has argued that when introducing coaching within organizations, the 'bottom up' potential is empowering and can lead to significant personal and professional benefits. Hoda, Noble, and Marshall (2010) also recognize the important role of the champion. Organizations may want to harness the energy that champions bring to the organization and encourage and resource them to introduce formal coaching.

\section{Conclusion}

Our intention in this research was to contribute to the future development of project managers through an exploratory understanding of how project managers think about and use coaching. Findings suggest that coaching is considered useful for developing skills, and is a means to support others through one-to-one relationships or group shared practice. There is emphasis on coaching as a helping relationship that is generative rather than instructional. Some confusion between coaching and mentoring, however, is evident. We would therefore encourage a more formalized approach to coaching, which includes explicit contracting where the basis of the relationship is agreed on at the outset.

This article reported on a small qualitative study of project managers' perceptions; therefore, the findings should be considered within the limitations of size and context. However, a number of areas for further research have been identified. First, we consider that additional understanding of project managers' experiences of coaching seems important. Surveys to establish what specific benefits they see from coaching and the reasons to promote coaching could help identify the motivators for becoming a champion and highlight useful features of the journey from awareness to champion. Second, in this study there seemed to be advantages from being a coach as well as from being coached. Findings suggested, for example, that there could be advantages for the development of soft skills for project managers, which are often seen as lacking. Such advantages could be researched in more detail in order to understand the specific benefits of coaching for project managers.

\section{References}

Adkins, L. (2010). Coaching agile teams: A companion for ScrumMasters, agile coaches, and project managers in transition. Boston, MA: Addison-Wesley Professional.

Allan, P. (2007). The benefits and impacts of a coaching and mentoring programme for teaching staff in secondary school. International Journal of Evidence Based Coaching and Mentoring, 5(2), 12-21.
Anderson, M. C., Frankovelgia, C., \& Hernez-Broome, G. (2009). In focus/ coaching: Business leaders reflect on coaching cultures. Leadership in Action, 28(6), 20-22.

Anderson, D. L., \& Anderson, M. C. (2005). Coaching that counts: Harnessing the power of leadership coaching to deliver strategic value. Burlington, MA: Elsevier Butterworth-Heinemann.

Beattie, R. S., Kim, S., Hagen, M. S., Egan, T. M., Ellinger, A. D., \& Hamlin, R. G. (2014). Managerial coaching: A review of the empirical literature and development of a model to guide future practice. Advances in Developing Human Resources, 16(2), 184-201.

Berg, M. E., \& Karlsen, J. T. (2007). Mental models in project management coaching. Engineering Management Journal, 19(3), 3-13.

Box, S., \& Platts, K. (2005). Business process management: Establishing and maintaining project alignment. Business Process Management Journal, 11(4), 370-387.

Brill, J. M., Bishop, M. J., \& Walker, A. E. (2006). The competencies and characteristics required of an effective project manager: A web-based Delphi study. Educational Technology Research and Development, 54(2), 115-140.

Carbone, T. A., \& Gholston, S. (2004).

Project manager skill development: A survey of programs and practitioners. Engineering Management Journal, 16(3), 10-16.

Carbone, T. A., \& Tippett, D. D.

(2004). Project risk management using the project risk FMEA. Engineering Management Journal, 16(4), 28-35.

Charmaz, K. (2014). Constructing grounded theory: A practical guide through qualitative analysis. London, England: Sage.

Chartered Institute of Personnel and Development. (2005, 2006, and 2007). Training and development: Annual Survey Report 2005, 2006, and 2007, London, England: CIPD.

Chartered Institute of Personnel and Development. (2011). The learning and 
talent development annual survey report 2011. London, England: CIPD.

Clutterbuck, D. (2013). Time to focus coaching on the team. Industrial and Commercial Training, 45(1), 18-22.

Clutterbuck D. (2014). Team coaching. In Cox E., Bachkirova T., Clutterbuck D. (2014), The complete handbook of coaching (pp. 271-284). London, England: Sage.

Clutterbuck, D., \& Megginson, D. (2005). Making coaching work: Creating a coaching culture. London, England: CIPD Publishing.

Cox, E. (2012). Individual and organizational trust in a reciprocal peer coaching context. Mentoring \& Tutoring: Partnership in Learning, 20(3), 427-443.

Cox, E. (2013). Coaching understood, London, England: Sage.

Cox, E., Bachkirova, T., \& Clutterbuck, D. A. (Eds.). (2014a). The complete handbook of coaching. London, England: Sage.

Cox, E., Bachkirova, T., \& Clutterbuck, D. (2014b). Theoretical traditions and coaching genres: Mapping the territory, Advances in Developing Human Resources, 16(2) 139-160.

Edwards, J., Snowden, M., \& Halsall, J. (2016). Coaching works! A qualitative study exploring the effects of coaching in a public sector organisation. The Journal of Social Sciences Research, 2(5), 88-92.

Egan, T., \& Hamlin, R. G. (2014). Coaching, HRD, and relational richness: Putting the pieces together. Advances in Developing Human Resources, 16(2), 242-257.

Ellinger, A. D., Beattie, R. S., \& Hamlin, R. (2014). The manager as coach. In: E. Cox, T. Bachkirova, \& D. Clutterbuck (eds.), The complete handbook of coaching (pp. 256-270). London, England: Sage.

Evans, G. (2011). Second order observations on a coaching programme: The changes in organisational culture. International Journal of Evidence Based Coaching and Mentoring, (5), 70-87.

Feldman, D. C., \& Lankau, M. J. (2005). Executive coaching: A review and agenda for future research. Journal of Management, 31(6), 829-848.

Ferrar, P. (2006). The paradox of manager as coach: Does being a manager inhibit effective coaching? Unpublished master's thesis. Oxford, UK: Oxford Brookes University.

Fillery-Travis, A. (2015). Contracting within the business coaching relationship: A guide and a cautionary tale! Discussion Paper. Worldwide Association of Business Coaches, Canada. Retrieved from http:// eprints.mdx.ac.uk/14318/

Garvey, B. (2014). Mentoring in a coaching world, in E. Cox, T. Bachkirova \& D. Clutterbuck (Eds.), The complete handbook of coaching. London, England: Sage.

Garvey, B., Stokes, P., \& Megginson, D. (2014). Coaching and mentoring: Theory and practice. London, England: Sage.

Giberson, T. R., Resick, C. J., Dickson, M. W., Mitchelson, J. K., Randall, K. R., \& Clark, M. A. (2009). Leadership and organizational culture: Linking CEO characteristics to cultural values. Journal of Business and Psychology, 24(2), 123-137. Gillard, S. (2009). Soft skills and technical expertise of effective project managers. Issues in Informing Science and Information Technology, 6(7), 723-729.

Gormley, H., \& van Nieuwerburgh, C. (2014). Developing coaching cultures: A review of the literature. Coaching: An International Journal of Theory, Research and Practice, 7(2), 90-101.

Graham, R. J., \& Englund, R. L. (2013). Creating an environment for successful projects. Hoboken, NJ: John Wiley \& Sons.

Gregory, J. B., \& Levy, P. E. (2010). Employee coaching relationships: Enhancing construct clarity and measurement. Coaching: An International Journal of Theory, Research and Practice, 3(2), 109-123.

Hackman, J. R., \& Wageman, R. (2005). A theory of team coaching. Academy of Management Review, 30(2), 269-287.

Hagen, M., \& Gavrilova Aguilar, M. (2012). The impact of managerial coaching on learning outcomes within the team context: An analysis. Human Resource Development Quarterly, 23(3), 363-388.

Hans, R. T., \& Rwelamila, P. M. (2012). Knowledge base of project managers in the South African ICT sector. Computer Science and Information Technology, 2. Retrieved from http://www.researchgate. net/profile/Pantaleo_Rwelamila/ publication/266501550_KNOWLEDGE_ BASE_OF_PROJECT_MANAGERS_IN_ THE_SOUTH_AFRICAN_ICT_SECTOR/ links/54f8801c0cf210398e96b386.pdf

Hawkins, P. (2012). Creating a coaching culture. Maidenhead, UK: Open University Press.

Hoda, R., Noble, J., \& Marshall, S. (2010, May). Organizing self-organizing teams. In Proceedings of the 32nd ACM/IEEE International Conference on Software Engineering-Volume 1 (pp. 285-294). New York, NY: Association for Computing Machinery.

International Coaching Federation (2015). Code of ethics. Retrieved from http://coachfederation.org/about/ethics. aspx?ItemNumber=854

Ives, Y. (2008). What is 'coaching?' An exploration of conflicting paradigms. International Journal of Evidence Based Coaching and Mentoring, 6(2), 100-113.

Jiang B. (2002). Key elements of a successful project manager. Project Management Journal, 8(1), 14-19.

Kombarakaran, F. A., Yang, J. A., Baker, M. N., \& Fernandes, P. B. (2008). Executive coaching: It works! Consulting Psychology Journal: Practice and Research, 60(1), 78-90.

Kretzschmar, L. (2010). Exploring clients' readiness for coaching. International Journal of Evidence Based Coaching \& Mentoring, Special Issue 4, 1-20.

Ladyshewsky, R. (2010). The manager as coach as a driver of organizational development. Leadership \& Organization Development Journal, 31(4), 292-306.

Lee, M. R. (2009). E-ethical leadership for virtual project teams. International Journal of Project Management, 27(5), 456-463.

McCarthy, G. (2015). Coaching for responsible management. 18th Annual 
Irish Academy of Management Conference. Retrieved from http://ro .uow.edu.au/cgi/viewcontent.cgi?article $=1830 \&$ context=buspapers

McComb, C. (2012). Developing coaching culture: Are your managers motivated coaches? (Part 1). Industrial \& Commercial Training, 44(2), 90-93.

McKee, A., \& Eraut, M. (Eds.). (2011). Learning trajectories, innovation and identity for professional development (Vol. 7). Berlin/Heidelberg, Germany: Springer Science \& Business Media.

Milner, J., \& McCarthy, G. (2016). Managerial coaching: A practical way to apply leadership theory? Retrieved from http://ro.uow.edu.au/cgi/viewcontent. cgi? article $=1825 \&$ context $=$ buspapers

Moe, N. B., Cruzes, D. S., Dyba, T., \& Engebretsen, E. (2015, July). Coaching a global agile virtual team. In Global Software Engineering (ICGSE), 2015 IEEE 10th International Conference on (pp. 33-37). New York, NY: Institute of Electrical and Electronic Engineers (IEEE).

Paasivaara, M., \& Lassenius, C. (2014). Agile coaching for global software development. Journal of Software: Evolution and Process, 26(4), 404-418.

Palm, K., \& Lindahl, M. (2015). A project as a workplace: Observations from project managers in four $R \& D$ and project-intensive companies. International Journal of Project Management, 33(4), 828-838.

Pant, I., \& Baroudi, B. (2008). Project management education: The human skills imperative. International Journal of Project Management, 26(2), 124-128.

Passmore, J., \& Fillery-Travis, A.

(2011). A critical review of executive coaching research: A decade of progress and what's to come. Coaching: An International Journal of Theory, Research and Practice, 4(2), 70-88.

Passmore, J., \& Jastrzebska, K. (2011). Building a coaching culture: A development journey for organisational development. Source: Coaching Review, 1(3), 89-101.
Pattinson, S., Preece, D., \& Dawson, P. (2016). In search of innovative capabilities of communities of practice: A systematic review and typology for future research. Management Learning, 47(5), 506-524.

Pollack, J., Costello, K., \& Sankaran, S. (2013). Applying actor-network theory as a sensemaking framework for complex organizational change programs. International Journal of Project Management, 31(8), 1118-1128.

Pousa, C. E., \& Mathieu, A. (2010). Sales managers' motivation to coach salespeople: An exploration using expectancy theory. International Journal of Evidence Based Coaching and Mentoring, 8(1), 34-50.

Project Management Institute (PMI). (2013). Pulse of the profession ${ }^{\circledR}$ : The high cost of low performance: The essential role of communications [report], Newtown Square, PA: Author. Retrieved from http://www.pmi.org/ /media/PDF/ Knowledge\%20Center/UK/2014-pulseof-profession-report.ashx

Raelin, J. A. (2012). The manager as facilitator of dialogue. Organization, 20(6), 818-839.

Ramazani, J., \& Jergeas, G. (2015). Project managers and the journey from good to great: The benefits of investment in project management training and education. International Journal of Project Management, 33(1), 41-52.

Savelsbergh, C. M., Havermans, L. A., \& Storm, P. (2016). Development paths of project managers: What and how do project managers learn from their experiences? International Journal of Project Management, 34(4), 559-569.

Savelsbergh, C. M., Poell, R. F., \& van der Heijden, B. I. (2015). Does team stability mediate the relationship between leadership and team learning? An empirical study among Dutch project teams. International Journal of Project Management, 33(2), 406-418.

Schmid, B., \& Adams, J. (2008). Motivation in project management: The project manager's perspective. Project Management Journal, 39(2), 60-71.
Stettina, C. J., \& Hörz, J. (2015).

Agile portfolio management: An empirical perspective on the practice in use. International Journal of Project Management, 33(1), 140-152.

Strauss A.L., \& Corbin J. M. (1990). Basics of qualitative research: Grounded theory procedures and techniques. London, England: Sage.

Thomas, J., \& Mengel, T. (2008). Preparing project managers to deal with complexity-Advanced project management education. International Journal of Project Management, 26(3), 304-315.

Turner, C., \& McCarthy, G. (2015). Coachable moments: Identifying factors that influence managers to take advantage of coachable moments in dayto-day management. 13(1), 1-15.

Walker, D., \& Dart, C. J. (2011).

Frontinus-A project manager from the Roman Empire era. Project Management Journal, 42(5), 4-16.

Williams, T. (2008). How do organizations learn lessons from projects-And do they? IEEE Transactions on Engineering Management, 55(2), 248-266.

Shirley Thompson is a doctoral student studying coaching and mentoring at Oxford Brookes University in Ringwood, Hants, United Kingdom. She was a project manager in software development at IBM until 2005 and now runs a small coaching practice in addition to volunteering with the PMI United Kingdom Chapter in mentoring and coaching activities. She can be contacted at shirley@ focussing-on-you.co.uk

Dr. Elaine Cox is principal lecturer and co-director of the International Centre for Coaching and Mentoring Studies at Oxford Brookes University, Wheatley, Oxford, United Kingdom, where she also directs the Doctor of Coaching and Mentoring Programme and supervises doctoral students. She is an experienced researcher, author, and editor and has recently published Coaching Understood (Sage). She is also the founding editor of The International Journal of Evidence Based Coaching \& Mentoring. She can be contacted at ecox@brookes.ac.uk 
This material has been reproduced with the permission of the copyright owner. Unauthorized reproduction of this material is strictly prohibited. For permission to reproduce this material, please contact PMI. 